\title{
Editorial: Using technology to enhance online learning
}

\author{
Cathy Malone \\ Middlesex University London
}

At the outset of the pandemic during the switch to emergency remote teaching there appeared to be a widespread misconception that the challenge facing the HE sector was primarily technological and the shift to online delivery simply required finding an appropriate digital translation of what was delivered face to face. The papers in this short section all explore uses of technology in a fine grained manner while refuting the simplistic technicist assumptions about learning, or that simple translation between modes of delivery is either desirable or possible. The authors here frame their challenges in terms of social learning: how do you measure and assess performance to an audience when all the theatres have closed? How do you maintain informal dialogic spaces for learning as a team or with your students when you can no longer meet? Posing questions which prioritise learning seems to have freed the authors here to be ambitious in addressing these challenges and galvanised teams to explore new technology to discover and create new online spaces through streaming and podcasting.

There is a sense of course deconstruction and reconstruction in the papers throughout this section where authors strip courses down to core elements and drivers in order to examine how best they can be reconstituted online. This process elicited a detailed evaluation of features and affordances for various online programmes (including Zoom, Teams and Articulate Rise, and combinations of these). This process also re-engaged authors in pedagogical theory (Laurillard and social constructivism are repeatedly mentioned), where theory is used as a means of sense making in a volatile environment.

It seems fitting to finish a section focusing on technology with a case study of a team working with dispersed groups of refugee learners facing significant digital poverty. There are a number of implications here regarding platform use, privacy and safety that will resonate with many tutors with a commitment to inclusive online delivery. Once again the 
authors demonstrate some considerable ingenuity in the adaptations they make to the challenges facing them.

Perusing these papers, it is evident that the challenge of Covid was at the same time an opportunity that engaged the authors of these pieces in live collaborative learning with their peers, and what began as a technological challenge became a route to a richer space for learning for staff and students alike.

\section{References:}

Hodges, C., Moore, S., Lockee, B., Trust, T., and Bond A. (2020) 'The difference between emergency remote teaching and online learning', Educause Review. Available at: https://er.educause.edu/articles/2020/3/the-difference-between-emergency-remoteteaching-and-online-learning (Accessed: 22 October 2021). 